\title{
AMIROUCHE AÏT HAMOUDA EN EL ARTE DE CHEDDANI YASSINE
}

\author{
Presentación de \\ Sarra Ikram Hadef
}

El artista urbano argelino Cheddani Yassine nació el 4 de junio de 1987 en la ciudad de Bouira. De origen amazigh, habla árabe dialectal, amazigh, francés e inglés. Es un pintor autodidacta que trabaja como decorador artesanal desde el 2015, después de terminar el bachillerato en Filosofía y Letras en 2009, y en Educación física en 2013. Yassine no ha tenido la oportunidad de trabajar como profesor en el ámbito educativo, y se dedica al campo de la decoración para ganarse la vida. Se enfrenta al espacio con diferentes materiales de pintura al óleo, lápiz y acrílico, utiliza cualquier tipo de técnica desde el realismo hasta el surrealismo abstracto.

Yassine suele dibujar para rellenar su vació, expresando opiniones sociales, políticas y filosóficas en sus dibujos. Intenta mantener nuevas técnicas en este vasto campo de expresión moderna, pero no encuentra el clima propicio donde exponer sus obras, como sucede con muchos artistas en el medio urbano de nuestros días.

Una de sus técnicas más vanguardistas es el dibujo con bolígrafo electrónico, lo que le permite una expresión más allá del lienzo o el espacio físico, y una transmisión inmediata a través de las redes sociales. Como cualquier otro artista anónimo de nuestro mundo global, la expresión urbana, el grafiti y el dibujo vectorial suelen ser obras intranscendentes que no pasan a los libros de historia. No obstantes, queremos con este ejemplo dar testimonio de una realidad que también es argelina. En este caso, el uso emblemático de Amirouche Aït Hamouda (I926-I959), importante figura de la Revolución argelina, cuya carga semántica sigue siendo productiva en nuestros días.

Como pintor bereber, Yassine recuerda la figura de $\mathrm{i}\left[<\mathrm{O}_{\circ} \mathrm{C}_{\circ}+\right.$ K[ᄃ:^^, en árabe: 'Amīrūš Āyat Ḥamūda, nacido el 31 de octubre de 1926 en Tassaft Ouguemoun, y muerto en combate al sur de Boussada el 28 de marzo de I959, apodado por los franceses "el lobo de Akfadou (pueblo 
amazigh)" y "Amirouche el terrible", coronel del Ejército de Liberación Nacional (ALN) y jefe de la wilaya in durante la guerra de independencia de Argelia. En el verano de 2019 pinto en la pared de un hotel de Boumerdes un grafiti con la silueta de Amirouche sobre la bandera argelina. Su objetivo era revivir a este personaje, desde una perspectiva nacionalista y bereber. Con diseño similar, realizó en el teléfono móvil un dibujo vectorial en el verano de 2020.

Para conocer más sobre esta figura de la Guerra de liberación argelina puede consultarse Muḥammad Șālaḥ Șadīq, al-'Aqìd 'Amīrūšs, Argel, Dār al-Umma, I999.
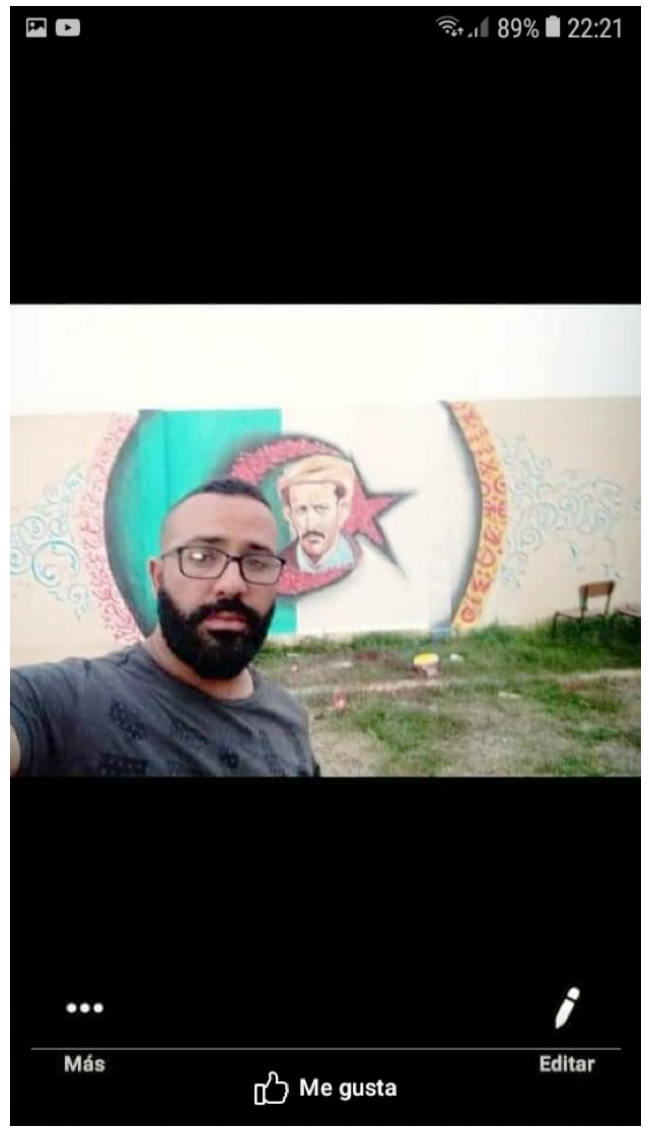

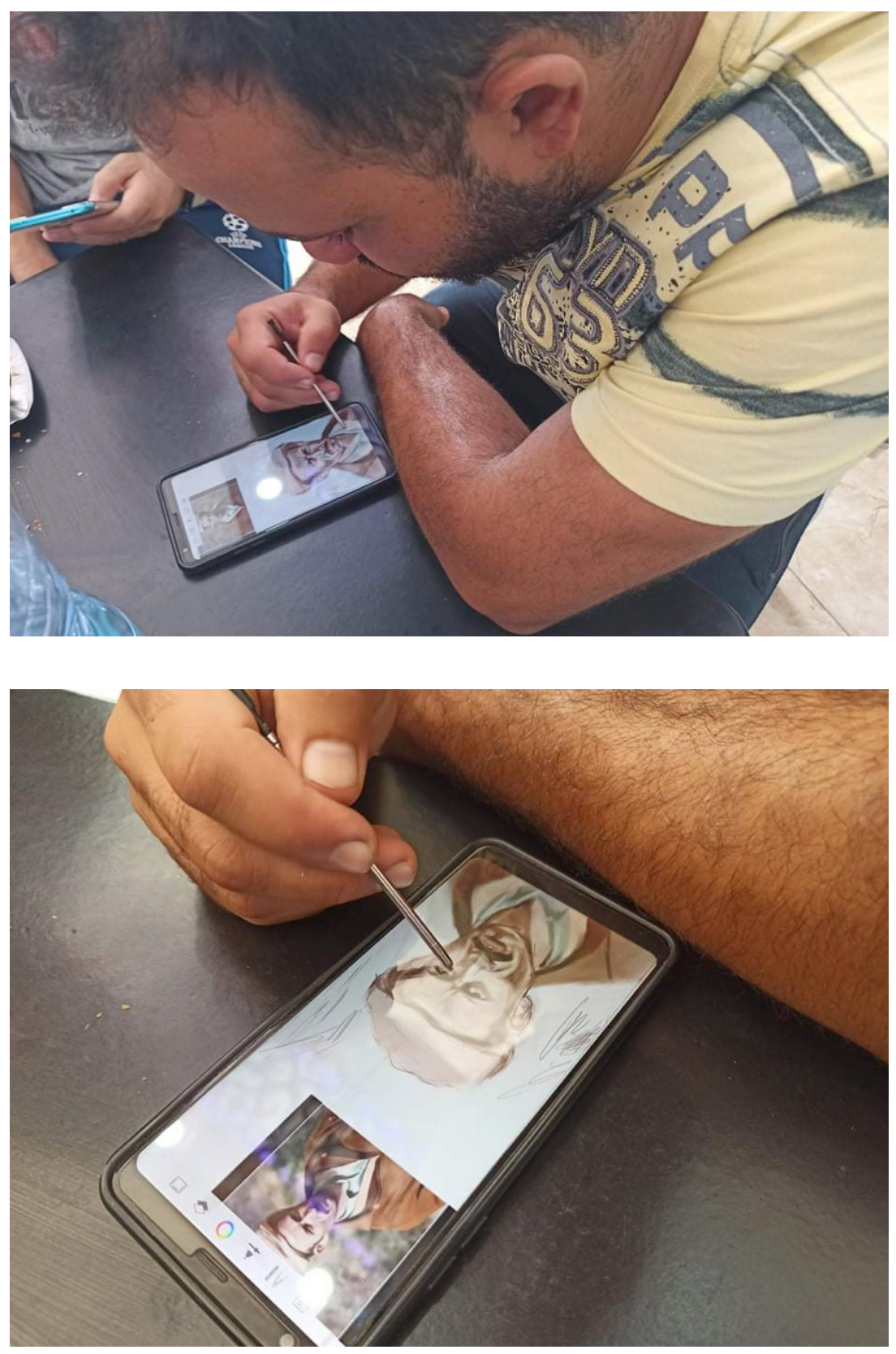
212 Sarra Ikram HadeF

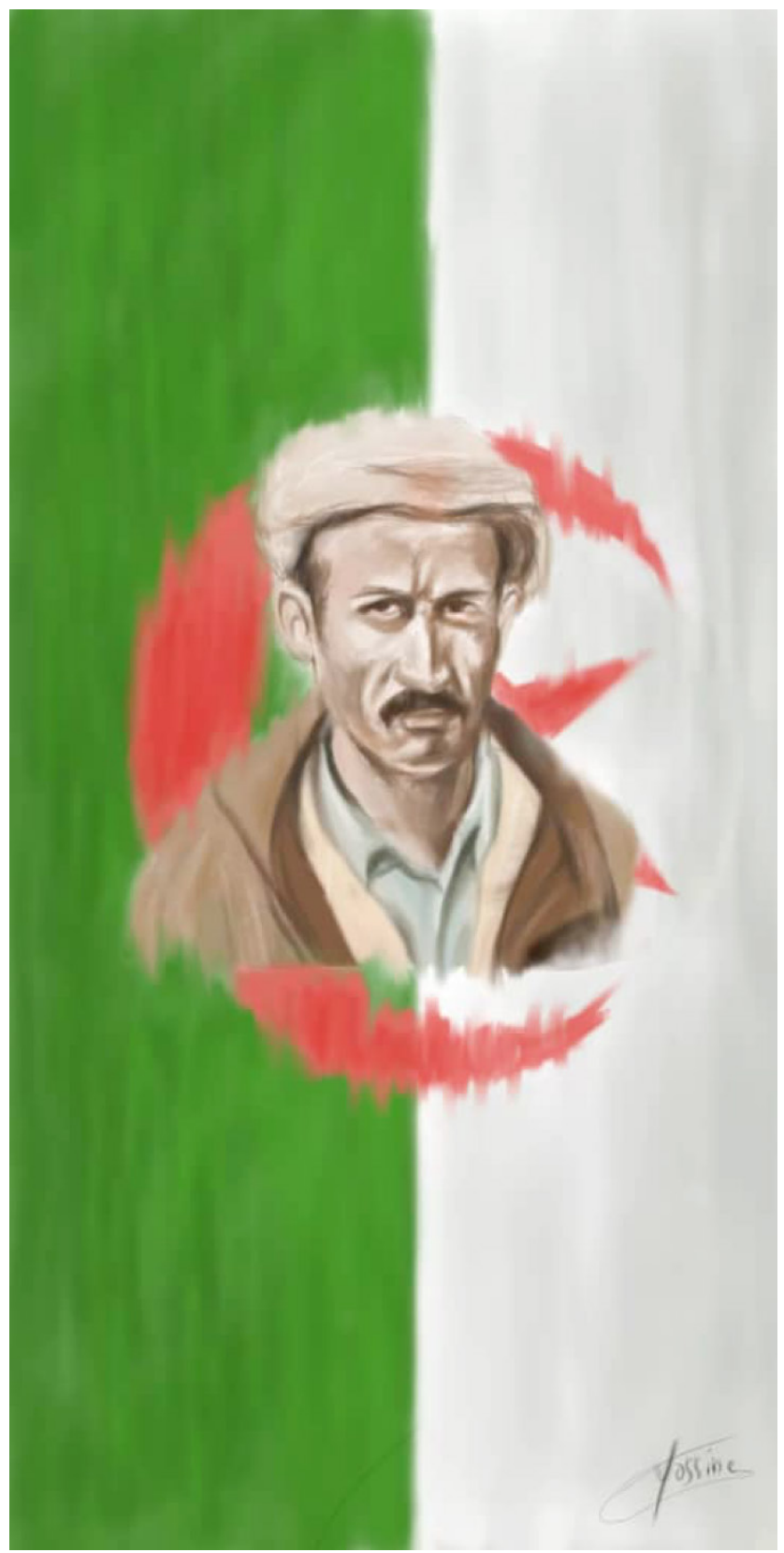

